Revista Energia na Agricultura

ISSN 1808-8759

\title{
CONSUMO DE COMBUSTÍVEL DE UM TRATOR AGRÍCOLA NO PREPARO DO SOLO PARA A CULTURA DO ALGODÃO IRRIGADO EM FUNÇÃO DA PRESSÃO DE INFLAÇÃO NOS PNEUS ${ }^{1}$ \\ GUSTAVO KIMURA MONTANHA ${ }^{2}$; SAULO PHILIPE SEBASTIÃO GUERRA ${ }^{3}$; PEDRO ANDRA-
DE-SANCHEZ ${ }^{4}$; FERNANDO HENRIQUE CAMPOS ${ }^{5}$ \& KLÉBER PEREIRA LANCCAS $^{6}$
}

RESUMO: Atualmente a eficiência nas operações de campo e o aumento na produtividade das culturas só são possíveis com o uso de máquinas e equipamentos agrícolas. Essa intensificação de atividades mecanizadas na agricultura, contudo, acarretou maiores gastos energéticos nas propriedades rurais principalmente no consumo de combustível dos tratores agrícolas. O objetivo do trabalho foi comparar o consumo de combustível de um trator agrícola no preparo do solo na cultura do algodão irrigado em região semi-árida variando-se duas pressões de inflação nos pneus. Os ensaios foram realizados na Maricopa Agricultural Center (MAC), fazenda experimental pertencente à The University of Arizona utilizando um trator Case 4x2 TDA de 88kW equipado com sistema de piloto automático. Os resultados evidenciaram menores valores no consumo horário de combustível utilizando a menor pressão de inflação de 124 kPa para todos os equipamentos de preparo de solo utilizados.

Palavras-chave: Ensaio de máquinas, mecanização agrícola, agricultura de precisão.

\footnotetext{
${ }^{1}$ Parte da dissertação de mestrado do $1^{\circ}$ autor intitulada: Avaliação do Consumo Energético no Preparo de Solo para a Cultura do Algodão Irrigado.

${ }^{2}$ Aluno do Programa de Pós-Graduação em Energia na Agricultura, Faculdade de Ciências Agronômicas FCA/UNESP, Botucatu/SP - Brasil, gmontanha@fca.unesp.br

${ }^{3}$ Orientador e Docente do Departamento de Gestão e Tecnologia Agroindustrial da Faculdade de Ciências Agronômicas - FCA/UNESP, Botucatu/SP - Brasil, ssguerra@fca.unesp.br

${ }^{4}$ Co-orientador e Docente do Departamento de Engenharia Rural da Maricopa Agricultural Center - MAC/The University of Arizona, Maricopa/AZ - EUA, pandrade@ag.arizona.edu

${ }^{5}$ Aluno do Programa de Pós-Graduação em Energia na Agricultura, Faculdade de Ciências Agronômicas FCA/UNESP, Botucatu/SP - Brasil, fhcampos@fca.unesp.br

${ }^{6}$ Docente do Departamento de Engenharia Rural da Faculdade de Ciências Agronômicas - FCA/UNESP, Botucatu/SP - Brasil, kplancas@fca.unesp.br
} 


\section{FUEL CONSUMPTION OF AN AGRICULTURAL TRACTOR ON TILLAGE OPERATIONS FOR IRRIGATED COTTON AS FUNCTION OF TIRE INFLATION PRESSURE}

SUMMARY: Currently, the efficiency in field operations and the increased productivity of crops is only possible with the use of agricultural machinery and equipment. This intensification of mechanized activities in agriculture, however, led to higher energy costs on farms mainly in the fuel consumption of agricultural tractors. The objective was to compare the fuel consumption of a tractor on tillage operations for irrigated cotton in semi-arid region varying two tire inflation pressures. The tests were conducted in Maricopa Agricultural Center (MAC), an experimental farm belonging to The University of Arizona using a $4 \times 2$ TDA Case tractor equipped with a 88kw autopilot system. The results showed lower values in the hourly fuel consumption by using the minimum tire inflation pressure of $124 \mathrm{kPa}$ for all tillage equipment used.

Keywords: Test, mechanization, precision agriculture.

\section{INTRODUÇÃO}

A cultura do algodão está entre as dez principais do mundo sendo cultivada economicamente em mais de 60 países, e em regiões semi-áridas, caracteriza-se por apresentar altos custos de produção, alta dependência de processos mecanizados, baixos índices pluviométricos e rigorosos critérios de avaliação de qualidade.

Nos Estados Unidos, a cadeia do algodão é a quinta em geração de valor dentre as cadeias agrícolas, o que confere poder econômico e político considerável aos seus agentes. Os principais estados americanos produtores são o Texas, Mississippi e Califórnia, e as principais espécies cultivadas são o Upland (Gossypium hirsutum) e a Pima (Gossypium barbadense). Cerca de 40\% da produção do algodão é cultivada sob irrigação e mais de 90\% é colhida mecanicamente onde mais de 95\% utiliza variedades transgênicas resistentes a insetos (BUAINAIN, 2007).

O desenvolvimento da agricultura atual está diretamente ligado à intensificação de atividades mecanizadas no campo e do uso de novas tecnologias de agricultura de precisão voltadas para a agricultura, sendo o trator agrícola um dos fatores de maior importância responsável por transformar energia química contida nos combustíveis, em energia mecânica, através da força produzida na barra de tração, utilizada para tracionar máquinas agrícolas e torque na TDP para acionar equipamentos. 
De acordo com Molin (2004) a agricultura de precisão, que era vista como um conjunto de ferramentas para o manejo localizado da lavoura, mais recentemente tem merecido uma definição mais sistêmica. É acima de tudo, uma nova forma de gestão ou de gerenciamento da produção agrícola. É um elenco de tecnologias e procedimentos utilizados para que as lavouras e os sistemas de produção sejam otimizados, tendo como elemento chave o gerenciamento da variabilidade espacial da produção e dos fatores nela envolvidos.

Em relação aos benefícios proporcionados pela agricultura de precisão, Antuniassi et al. (2007), afirmou que em termos econômicos, a utilização desta tecnologia possibilitou a priorização de investimentos em áreas onde o potencial de produção seja mais efetivo, garantindo maior retorno econômico. Do ponto de vista ambiental, a racionalização e a redução do uso de insumos devem ser avaliadas como principais benefícios da agricultura de precisão.

O piloto automático é um sistema de direcionamento via satélite acoplado ao sistema hidráulico do trator agrícola capaz de fornecer correções de direcionamento durante as operações de campo evitando erros de sobreposição e falhas.

O preparo de solo compreende um conjunto de práticas que têm como objetivo a preservação das características físicas, químicas e biológicas do solo, oferecendo condições ideais para semeadura, germinação e desenvolvimento das plantas. Esta operação é considerada uma das mais importantes no manejo do solo, pois o uso excessivo de implementos inadequados rapidamente degradam o solo. Portanto, é necessário planejar o uso racional com implementos adaptados às condições e tipos de solo, procurando manter ou aumentar o seu potencial produtivo (EMBRAPA, 2010).

As operações necessárias e os métodos de preparo variam principalmente em função das condições e do tipo solo, da declividade do terreno e dos recursos mecanizados disponíveis, sendo importante também a eliminação dos restos da vegetação anterior.

O consumo de combustível do trator agrícola engloba um dos custos mais elevados nas operações agrícolas sendo que o total consumido está diretamente ligado a fatores como a adequação e condição do conjunto trator-equipamento, profundidade da operação, tipo e condição de solo, número total de operações utilizadas no processo de preparação do solo dentre outros.

Diversos métodos podem ser considerados ao se estudar o desempenho de máquinas agrícolas. Os métodos diretos são assim denominados porque decorrem da instrumentação e monitoramento das máquinas, permitindo a determinação dos fatores que otimizam os seus desempenhos, tais como: capacidade operacional, eficiência e consumo de combustível (CORDEIRO, 2000).

De acordo com Mialhe (1996), a mensuração da quantidade de combustível consumida, constituise um dos mais importantes aspectos da avaliação do rendimento de um motor, ou seja, do seu desempenho como máquina térmica conversora de energia. O consumo de combustível pode ser expresso de duas 
maneiras: em relação ao tempo (L.h $\mathrm{h}^{-1}$; kg.h ${ }^{-1}$, etc) e em relação ao trabalho mecânico desenvolvido (consumo específico $=\mathrm{g} \mathrm{cv} \cdot \mathrm{h}^{-1} ; \mathrm{g} \mathrm{kW} \cdot \mathrm{h}^{-1}$, etc). O consumo horário geralmente é obtido por leitura direta de instrumentos de mensuração que podem ser expressas em termos ponderais $\left(\mathrm{kg} . \mathrm{h}^{-1}\right)$ ou volumétrico $\left(\mathrm{L} \cdot \mathrm{h}^{-1}\right)$.

Dentre os fatores que podem influenciar o rendimento energético de um trator agrícola, o pneu agrícola surge como um dos mais importantes, pois além de garantir o equilíbrio, o deslocamento, o direcionamento e o amortecimento do trator, também está diretamente ligado nos seus resultados de desempenho operacional. A utilização correta do tipo de construção dos pneus, da pressão de inflação utilizada e da carga aplicada pode influenciar diretamente na eficiência produtiva e no consumo combustível do trator.

Segundo Franz (1988), os pneumáticos do trator constituem um de seus mais importantes componentes, pois tem a função de fornecer equilíbrio, vão livre, deslocamento, direcionamento e esforço tratório. Lee e Kim (1997) afirmaram ainda que a pressão de inflação tem papel fundamental na área de contato entre o pneu e o solo, além da distribuição de pressão na sua superfície.

Pneus com baixa pressão de inflação tendem a ter maior área de contato com o solo, fornecendo ao trator maior capacidade tratória. Correa et al. (2000) observaram uma tendência de melhoria na capacidade tratória, quando os pneus estavam inflados na pressão recomendada pelo fabricante. Os resultados obtidos pelos autores evidenciaram diferenças expressivas do uso da pressão correta em relação às altas pressões de inflação, com redução de $11,5 \%$ na patinagem e de 3,2\% no consumo de combustível do trator. Os autores obtiveram ainda um aumento de 3,7\% na potência na barra de tração e de 4,4\% na capacidade operacional, com o uso da pressão recomendada pelo fabricante de pneus comparado com a pressão baixa em pneus diagonais.

Lanças et al. (1995) estudaram os efeitos de pneus radiais em rodagem dupla 20.8 R 48 em ambos eixos de tração em condições de campo com trator 4X4, para duas estações do ano (primavera e verão) em solo da Califórnia (EUA). Os testes realizados na primavera, foi realizado em um solo relativamente seco denominado Capay clay em um campo de arroz localizado em Woodland (EUA). Os testes realizados no verão, foram realizados em um solo denominado Ricon silt clay/yolo silt loan na Universidade de DavisCalifórnia. Os resultados mostraram que, com pressão correta/baixa ocorreram menor consumo de combustível, menor compactação do solo, maior desempenho operacional e maior capacidade de campo. A pressão de inflação reduzida tem sido recomendados pelos fabricantes de pneus agrícolas.

A partir dessas observações o presente trabalho teve como objetivo, comparar o consumo de combustível de um trator agrícola variando-se duas pressões de inflação nos pneus para dois tipos diferentes de solo utilizando o equipamento de preparo de solo canteirador para a cultura do algodão irrigado em regiões semi-áridas. 


\section{MATERIAL E MÉTODOS}

Os ensaios foram realizados no Maricopa Agricultural Center - MAC, pertencente à The University of Arizona localizada na cidade de Maricopa estado do Arizona, Estados Unidos. A área utilizada está localizada entre as coordenadas geográficas UTM $33^{\circ} 05^{\prime} \mathrm{S}$ e $111^{\circ} 97^{\prime} \mathrm{W}$ e altitude de $430 \mathrm{~m}$, com classificação de textura de solo franco argilo arenosa (52\% areia, 35\% argila, 13\% silte).

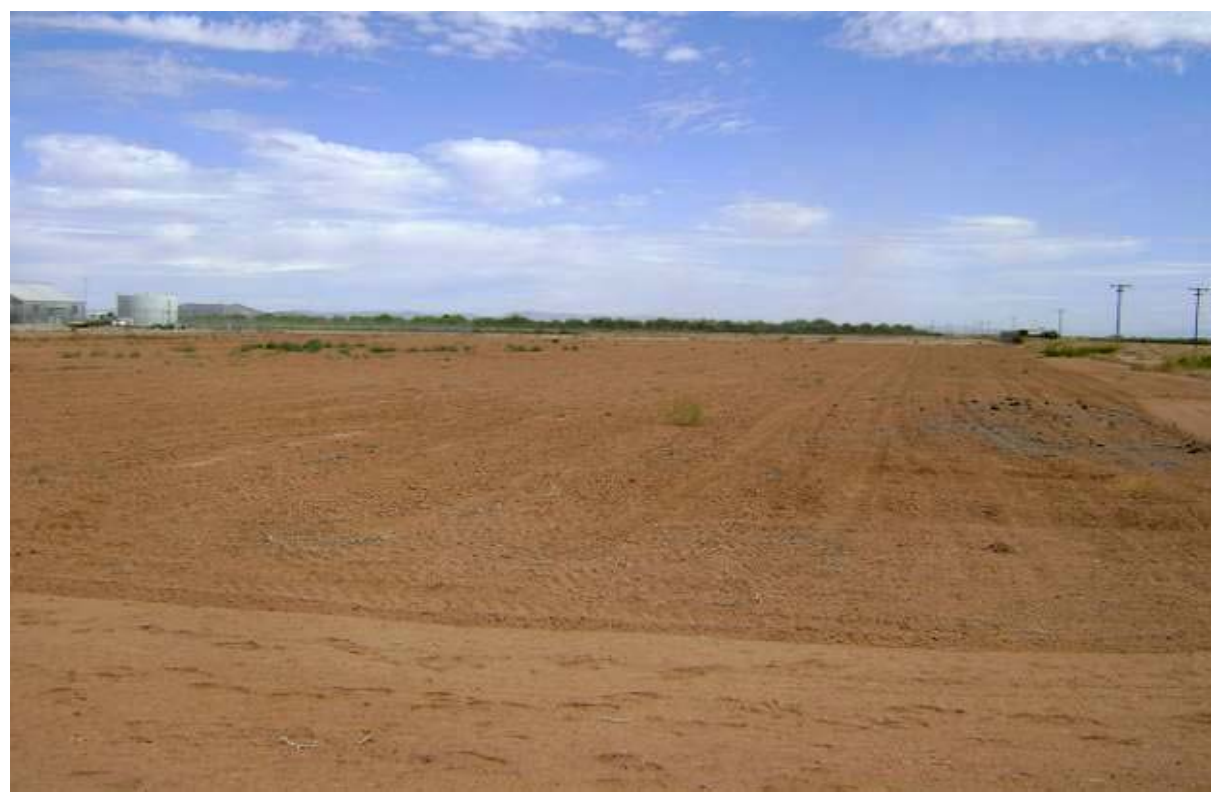

Figura 1 - Vista parcial da área.

Para a realização de todos os ensaios foi utilizado um trator agrícola da marca Case, modelo MXM 120, 4x2 TDA, descrito na Tabela 1 e ilustrado na Figura 2.

Foi utilizado um sistema de direcionamento piloto automático modelo AgGPS Autopilot System desenvolvido pela empresa com sensores e equipamentos conectados junto ao sistema hidráulico de direção do trator que possibilitou o trajeto automático da máquina, sem necessariamente precisar da intervenção do operador, evitando assim sobreposições e falhas durante a realização dos ensaios. 


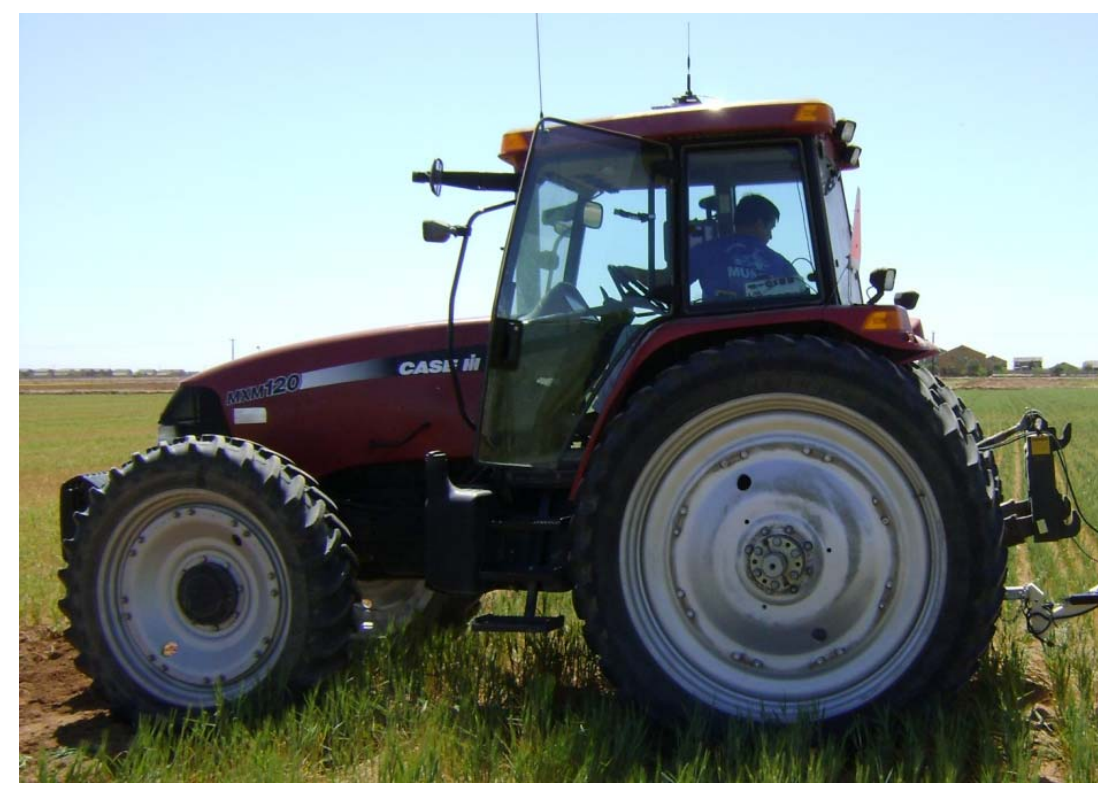

Figura 2 - Trator agrícola.

Tabela 1 - Especificações do trator.

\begin{tabular}{ll}
\hline \multicolumn{1}{c}{ Descrição } & \multicolumn{1}{c}{ Características } \\
\hline Marca & IH Case \\
Modelo & MXM 120 \\
Motor & 6 cilindros, 7,48L, turbo e intercooler \\
RPM máximo do motor & 2200 \\
RPM mínima do motor para 540 RPM TDP & 1969 \\
Capacidade de carga no sistema hidráulico & $4425 \mathrm{~kg}$ \\
Peso sem lastro & $5366 \mathrm{~kg}$ \\
\hline
\end{tabular}

Para a obtenção das coordenadas geográficas pelo GNSS (Global Navigation Satellite System), foi utilizado um receptor modelo AgGPS 332 da marca Trimble, apropriado para aplicações em agricultura de precisão, ilustrado na Figura 3 e descrito na Tabela 2. O receptor GNSS foi utilizado também no sistema de direcionamento de piloto automático do trator com sistema de correção diferencial cinemático em tempo real (RTK). 


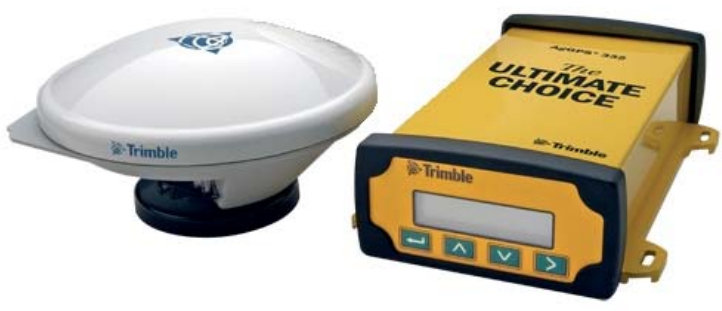

Figura 3 - Receptor e antena GNSS.

Tabela 2 - Especificações do receptor GNSS.

\begin{tabular}{|c|c|}
\hline Descrição & Características* \\
\hline Dimensões & $14,78 \mathrm{~cm}(\mathrm{~L}), 5,58 \mathrm{~cm} \mathrm{(A),} \mathrm{21,59cm} \mathrm{(P)}$ \\
\hline Alimentação & $350 m A-12 V$ DC \\
\hline Portas & 2 portas de conexão ambas com suporte RS-332 e CAN \\
\hline Canais & 12 canais de recepção, L1, L2 e C/A \\
\hline Mensagens NMEA & $\begin{array}{l}\text { GGA, GLL, GSA, GST, GSV, MSS, RMC1, ZDA, GRS, } \\
\text { PJK, PTNL PJT, PTNLID, PTNL, PTNL VHD, VGK, } \\
\text { VTG, PTNLDG, PTNLEV, PTNSLM, XTE, ZDA }\end{array}$ \\
\hline Freqüência de mensagens NMEA & Até $5 \mathrm{~Hz}$ \\
\hline
\end{tabular}

* Informações obtidas no manual de operação, fornecido pelo fabricante (TRIMBLE, 2009).

Para o preparo do solo utilizou-se o equipamento arado duplo com característica de trabalho para quatro linhas de cultura responsável pela mobilização inicial do solo (Figura 4).
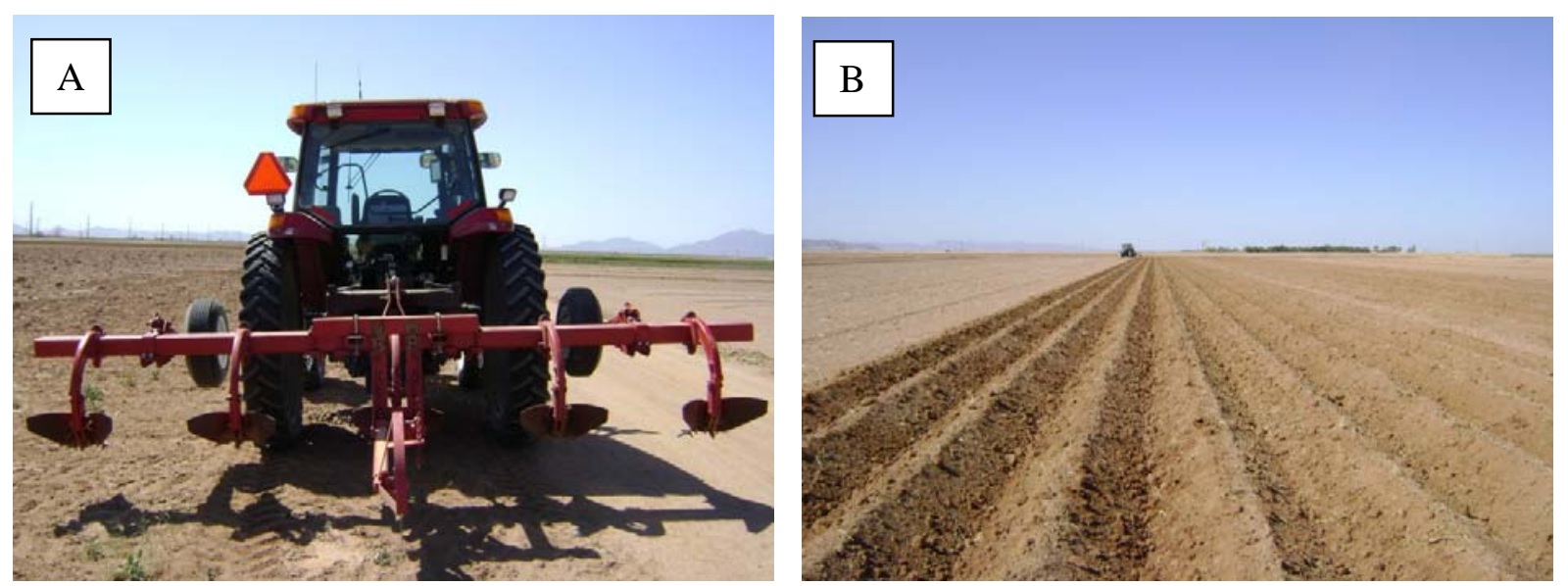

Figura 4 - Arado duplo (A) e área parcialmente mobilizada pelo equipamento (B). 
Após a mobilização inicial do solo realizou-se a formação dos canteiros com o equipamento canteirador para o plantio do algodão irrigado (Figura 5).
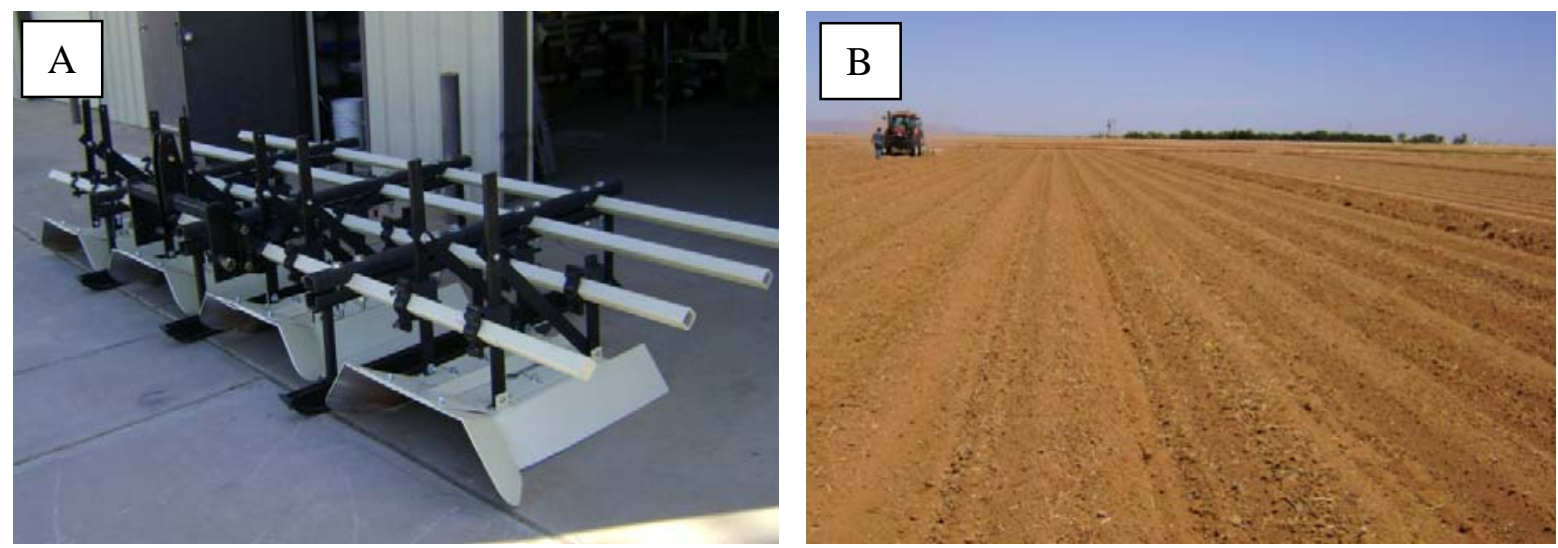

Figura 5 - Canteirador (A) e área parcialmente mobilizada pelo equipamento (B).

Os pneus utilizados foram da marca Michelin do tipo 320/85R38 dianteiros e 329/90R54 os traseiros. O consumo de combustível foi medido com a utilização de um sistema de medição de fluxo de combustível desenvolvido pela empresa Floscan Instrument Inc. modelo/série 7500/7600. O sistema consiste em dois fluxômetros, três reguladores de fluxo e um painel digital (Figura 6).
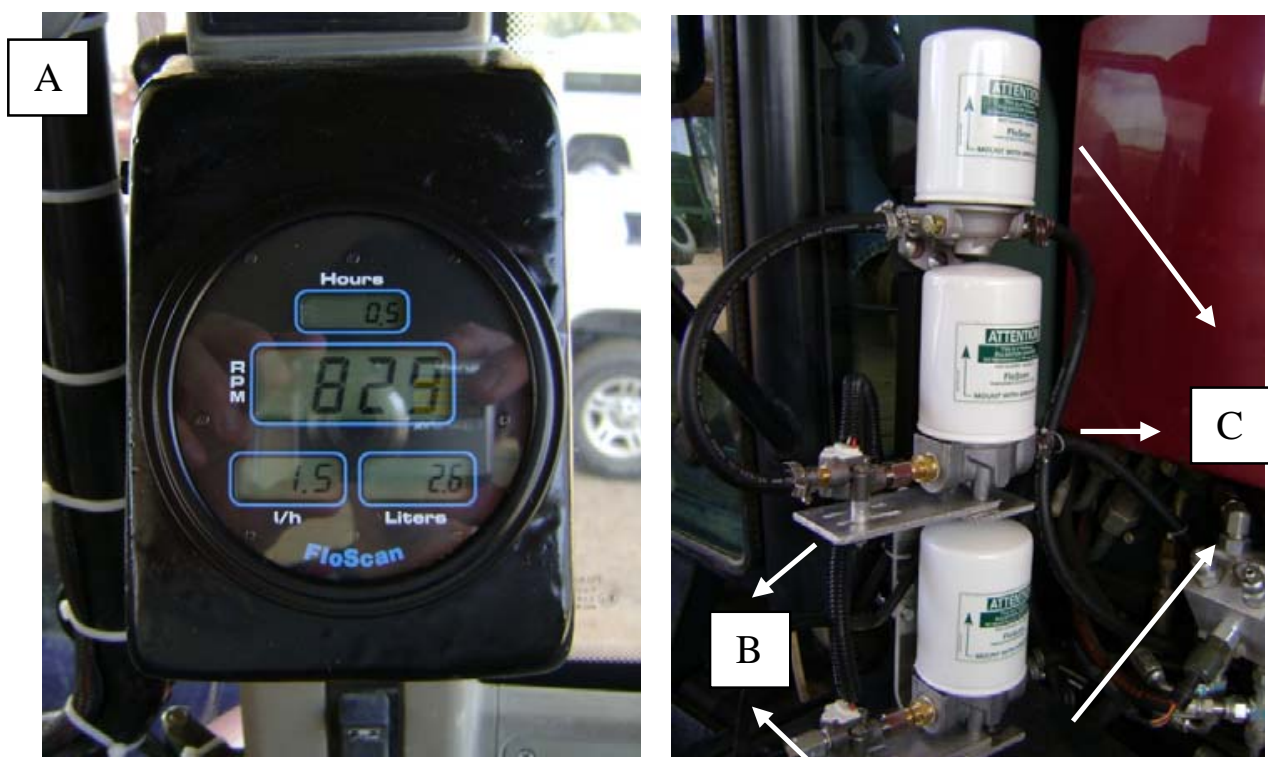

Figura 6 - Painel digital (A), fluxômetros (B) e reguladores de fluxo de combustível(C).

O sistema permitiu mensurar o consumo de combustível durante os ensaios determinando a diferença dos valores de fluxo em unidade de volume $(\mathrm{mL})$, antes do motor e durante o retorno do combustí- 
vel para o tanque. O sinal gerado pelo fluxômetro é um sinal de pulso com relação de um pulso por mL de combustível, alimentado por $12 \mathrm{~V}_{\mathrm{DC}}$.

O primeiro sensor foi instalado após o sistema de filtragem de combustível na linha de alimentação da bomba injetora e o segundo sensor no retorno de combustível do tanque (Figura 7).

As informações geradas pelos sensores foram processadas no painel digital, instalado na cabine do trator, que apresentam os valores do total de horas trabalhadas, rotações por minuto (RPM) do motor, consumo de combustível em litros por hora e consumo total de combustível em litros.

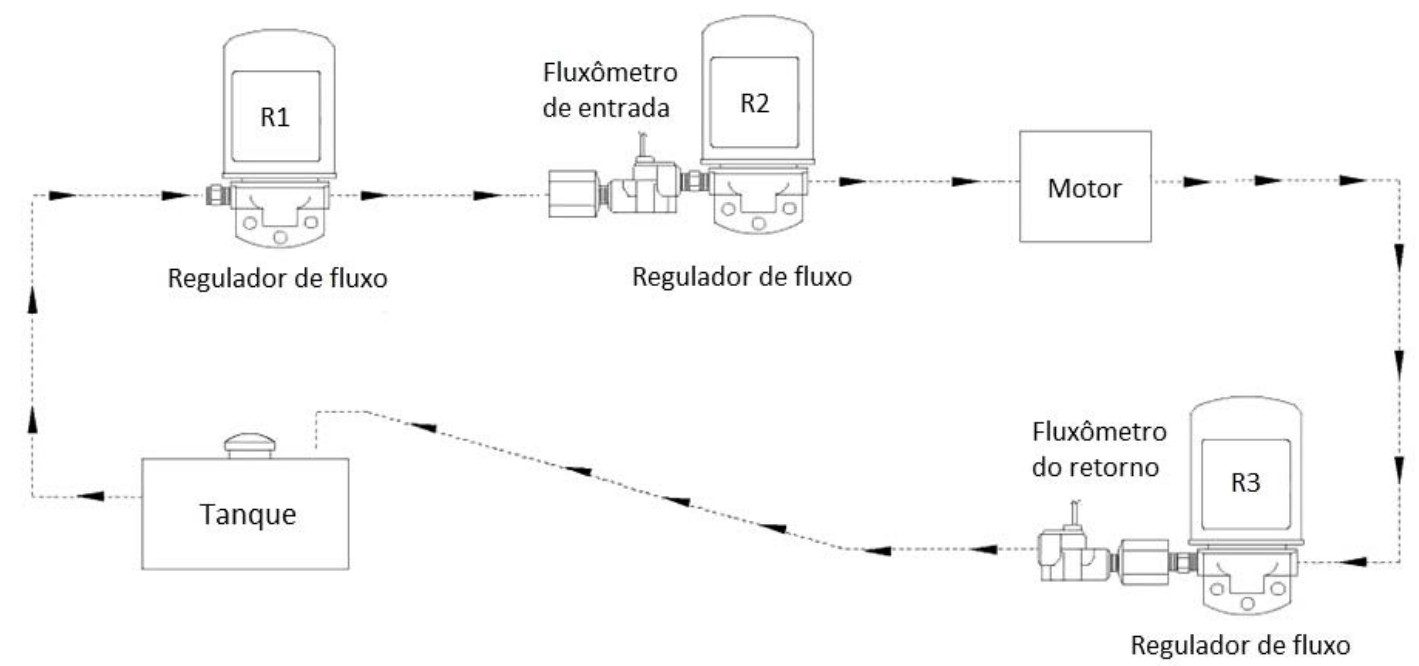

Figura 7 - Esquema de instalação dos fluxômetros e reguladores de fluxo.

Foi utilizado um sistema de aquisição de dados modelo CR3000 da marca Campbell Scientific (Figura 8). O sistema de aquisição de dados incorpora teclado alfanumérico e visor LCD para visualização de programas e dados podendo ser utilizado tanto em locais remotos e estacionários como em aplicações portáteis onde realiza o processamento de dados por meio de uma linguagem de programação.

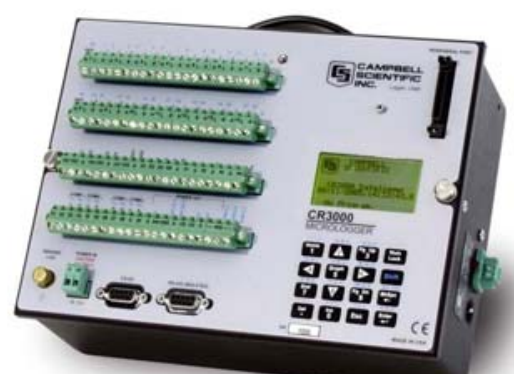

Figura 8 - Sistema de aquisição de dados. 
Os tratamentos foram definidos em função do tipo de textura de solo e da pressão de inflação nos pneus (Tabela 3). A rotação do motor foi 1600 rpm, constante em todas as repetições e a marcha utilizada foi a A-4 com velocidade média de deslocamento de $7 \mathrm{~km} \cdot \mathrm{h}^{-1}$.

Os dados gerados pelos sensores instalados no trator, foram armazenados no sistema de aquisição de dados com uma freqüência de aquisição de $2 \mathrm{~Hz}$ onde foram desenvolvidas linhas de comando utilizando a linguagem de programação CRBasic através do programa computacional Datalogger Support Software PC400 1.5 que determinaram as rotinas a serem executadas pelos dados coletados.

O sistema de aquisição de dados registrou os dados obtidos pelo receptor GNSS e os dados obtidos pelos fluxômetros. Pôde-se optar pela visualização das informações de consumo de combustível em tempo real por meio de um painel digital instalado dentro da cabine do trator que forneceu as informações: total de horas trabalhadas, rotações por minuto (rpm) do motor, consumo de combustível em litros por hora e consumo total de combustível em litros.

A velocidade média de deslocamento foi determinada a partir dos dados coletados pelo receptor GNSS. Para cada repetição, foi calculada a distância percorrida, subtraindo-se os dados de posição inicial pela posição final obtida pelo receptor GNSS. Para o cálculo do tempo decorrido foi subtraído o tempo final pelo tempo inicial. A velocidade de deslocamento $\left(\mathrm{Km}^{\mathrm{h}}{ }^{-1}\right)$ foi obtida de acordo com a Equação 1:

$V_{m r}=\left(\frac{s}{t}\right) * 3,6$

onde:

$\mathrm{V}_{\mathrm{mr}}$ - velocidade media da repetição $\left(\mathrm{Km} . \mathrm{h}^{-1}\right)$;

s - distância percorrida na repetição (m);

$\mathrm{t}$ - tempo decorrido na repetição (s)

3,6 - fator de conversão

Os pulsos gerados pelo fluxômetro volumétrico foram convertidos em volume, considerando a vazão de $1 \mathrm{~mL}$ por pulso e o tempo gasto na parcela. O cálculo do consumo horário de combustível foi realizado de acordo com a Equação 2:

$$
C_{h r}=\left(\frac{T p}{t}\right) * 3,6
$$

onde:

$$
\begin{aligned}
& \mathrm{C}_{\mathrm{hr}} \text { - consumo horário }\left(\mathrm{L} \cdot \mathrm{h}^{-1}\right) \\
& \mathrm{Tp} \text { - total de pulsos obtidos pelo fluxômetro; } \\
& \text { t - tempo decorrido na parcela (s) } \\
& \text { 3,6 - fator de conversão }
\end{aligned}
$$


Foram realizadas quatro repetições para cada tipo de pressão de inflação nos pneus totalizando 8 parcelas experimentais para cada implemento agrícola, arado duplo e canteirador. As pressões de inflação nos pneus utilizadas foram de 124 e 242 kPa (18 e 35psi).

\section{RESULTADOS E DISCUSSÃO}

Os dados obtidos com o equipamento arado duplo foram submetidos à análise de variância pelo teste $\mathrm{F}$ em função da pressão de inflação nos pneus ao nível de 5\% de probabilidade onde se observou diferença estatisticamente significativa entre as pressões de inflação nos pneus utilizada. Notou-se uma redução de 3\% no consumo horário de combustível utilizando a pressão mais baixa de $124 \mathrm{kPa}$ em relação à mais alta de $242 \mathrm{kPa}$ (Figura 9).

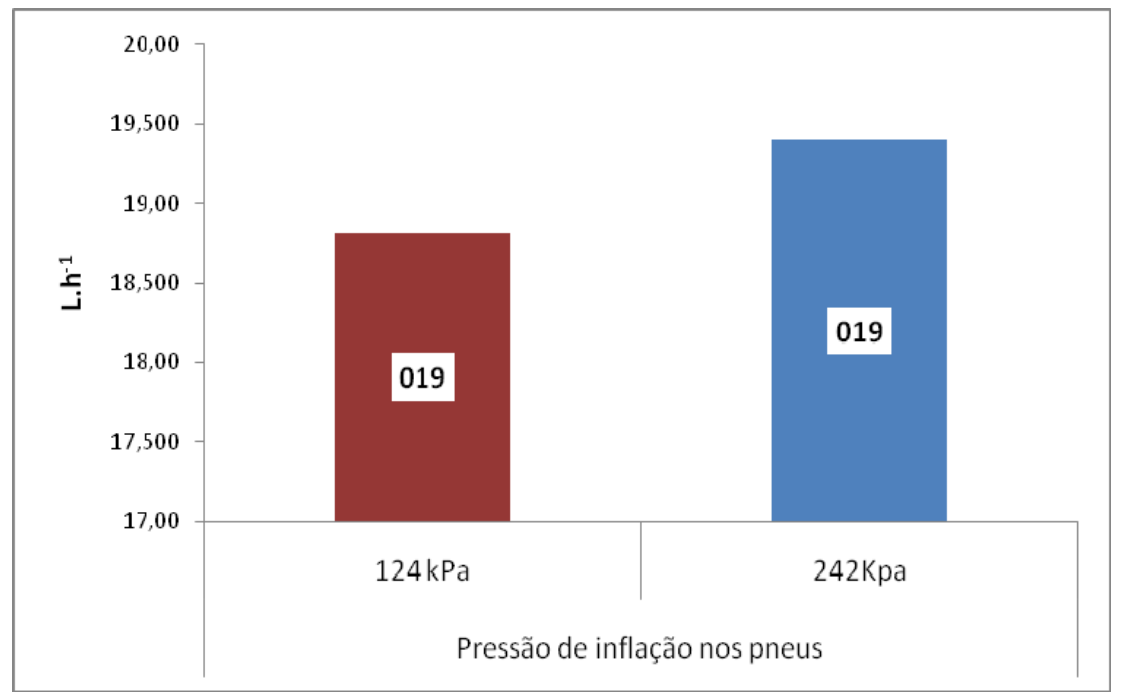

Figura 9 - Consumo horário de combustível utilizando o equipamento arado duplo.

Utilizando o equipamento canteirador observou-se também diferença estatisticamente significativa no consumo horário de combustível de 2,8\% utilizando a pressão mais baixa de 124 kPa (Figura 10), confirmando a hipótese de menores valores de consumo horário de combustível utilizando pressões mais baixas em pneus radiais, segundo citado por Lanças et al. (1995), Corrêa (2000) e Potier (1990). 


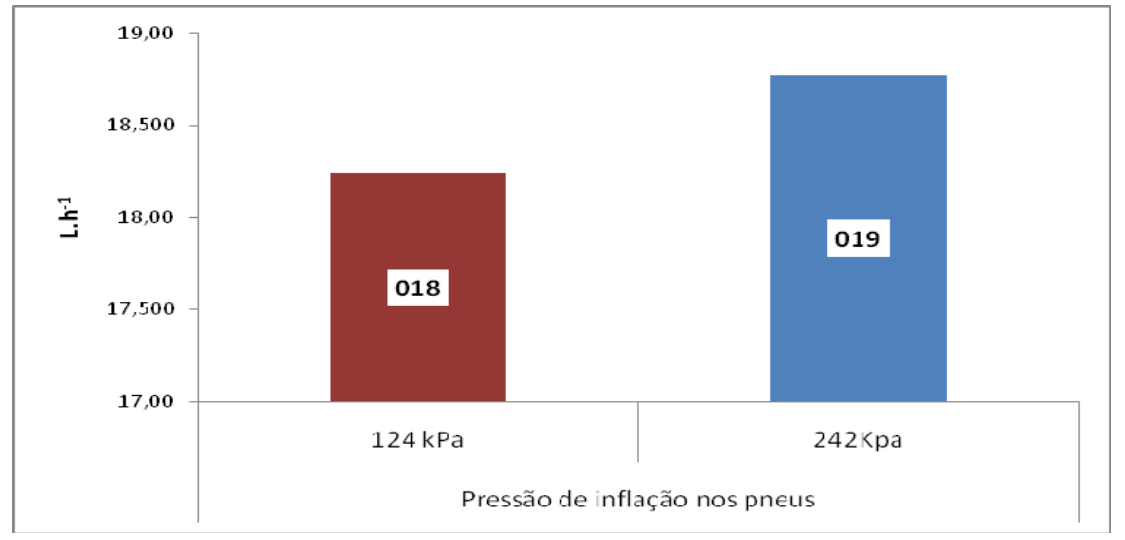

Figura 10 - Consumo horário de combustível utilizando o equipamento canteirador.

\section{CONCLUSÕES}

Para o preparo do solo na cultura do algodão irrigado em regiões semi-áridas, utilizando os equipamentos arado duplo e canteirador, o trator agrícola apresentou redução no consumo horário de combustível utilizando a menor pressão de inflação nos pneus de124 kPa.

\section{REFERÊNCIAS}

ANTUNIASSI, U. R, BAIO, F. H. R., SHARP, T. C. Algodão no cerrado do Brasil. 1. ed. Brasília, DF: ABRAPA, 2007. 934 p.

BUAINAIN, A. M., BATALHA, M. O. Cadeia produtiva do algodão: série agronegócios. 2 ed. Brasília: MAPA/SPA, 2007. 108p.

CORDEIRO M.A.L. Desempenho de um trator agrícola em função do pneu, da lastragem e da velocidade de deslocamento. Botucatu, UNESP-FCA, 2000. 153p. Tese (Doutorado em Agronomia - AC Energia na Agricultura) - Faculdade de Ciências Agronômicas, Universidade Estadual Paulista, 2000.

CORREA, I.M., LANÇAS, K.P. Desempenho operacional de pneus radiais de baixa pressão e 
pneus diagonais em trator 4x2 Aux. com a tração dianteira desligada. Energia na Agricultura, Botucatu, v. 15, n. 4, p. 44-55, 2000.

EMBRAPA. Cuidados básicos para o plantio mecanizado de soja em Rondônia. Disponível na <http://www.cpafro.embrapa.br/embrapa/infotec/soja.PDF> Acesso em 2 Jan 2010.

FRANZ, C. A. B. Avaliação do desempenho de pneumáticos para tratores agrícolas, com diferentes níveis de desgaste.Santa Maria-RS, 1988. 94 p. Dissertação (Mestrado em Agronomia) Universidade Federal de Santa Maria, 1988.

LANÇAS, K.P., SANTOS FILHO, G., UPADHYAYA, S.K. Implication of using low/correct inflation pressure for radial ply trator tires. St. Joseph, ASAE, 1995. (Paper AETC 95-056).

LANÇAS, K. P. Desempenho operacional de pneus radiais em função da pressão de inflação, da lastragem e do deslizamento das rodas de tratores agrícolas. Botucatu. 1996. Tese (Livre Docente) - Faculdade de Ciencias Agronomicas, Universidade Estadual Paulista “Julio de Mesquita Filho”.

LEE, D. R., KIM, K. U. Effect of inflation pressure on tractive performance of bias-ply tires. Journal of Terramechanics, ${ }^{\circ}$ 03, v. 34, p. $187-208,1997$.

MIALHE, L.G. Máquinas agrícolas: ensaios e certificação. Piracicaba, SP: Fundação de Estudos Agrários Luiz de Queiroz, 1996. 722p.

MOLIN, J. P. Utilização de GPS em Agricultura de Precisão. Eng. Agrícola, Jaboticabal, v.17, n.3, p.121-132, 2004.

POTIER, M. Pnues: la pression baisse. Agri-Décideur, Antony, n. 26, p. 15-28, oct., 1990. 